\title{
Tecendo quadros, poemas e utopias
}

\section{Cláudia Coelho ${ }^{1}$}

RESUMO: Este ensaio faz uma leitura comparativa entre alguns quadros do pintor catalão Joan Miró e alguns poemas de João Cabral de Melo Neto, buscando traços que remetem a expressões poéticas na pintura e visualidade na poesia, aproximando-a da expressão plástica, e ainda traços comuns que apontam para uma visão engajada da realidade.

ABSTRACT: This essay makes a comparison between some pictures of the Catalan painter Joan Miro and some poems by Joao Cabral de Melo Neto, seeking traits that refer to poetic expressions in painting and visual poetry, bringing it closer to the visual arts, and even common traits that point to a committed vision of reality.

PALAVRAS-CHAVE: João Cabral de Melo Neto; Joan Miró; expressão plástica; expressão poética; utopia

KEYWORDS: João Cabral de Melo Neto; Joan Miró; artistic expression; poetic expression; utopia.

João Cabral de Melo Neto afirmou, mais de uma vez, a importância das palavras concretas para a poeticidade. Tais palavras proporcionam uma visualidade plástica do texto que remete à arte pictórica. O poeta compõe uma poesia figurativa que possui a matéria concreta como centro. Essa visualidade é fruto da admiração nutrida por muitas leituras e estudos sobre a obra de matemáticos, engenheiros, arquitetos e, sobretudo, pintores, com os quais João Cabral desenvolveu relações de amizade.

1 Aluna do curso de pós-graduação, nível de doutorado, em Estudos comparados de literaturas de língua portuguesa, da USP, sob orientação do Prof. Benjamin Abdala Junior. 
$\mathrm{Na}$ Espanha, seguindo carreira diplomática, conheceu Joan Miró, de quem já admirava a obra pictórica. Foi tentando atender a uma encomenda de Josias Carneiro Leão, seu primo colecionador de artes, que João Cabral visitou pela primeira vez a casa do pintor Miró, em 1947. A tela d’ O galo não pode ser adquirida, por já estar catalogada na coleção particular do pintor, entretanto a amizade que surge nesta oportunidade ainda daria muitos frutos.

Em 1950, Cabral publica um ensaio intitulado Joan Miró (MELO NETO, 2003, p. 689-7200), em que revisita as pinturas prérenascentistas, lançando um olhar sobre a gênese da terceira arte, e caminha até o surgimento da perspectiva em terceira dimensão e do estatismo, que caracterizam a pintura renascentista. Cabral assevera que a expressão de um mundo em profundidade determina a busca incessante do equilíbrio pelos renascentistas. A contemplação de uma obra clássica conduz o olhar instantaneamente a um ponto ideal da tela, de onde é possivel apreender as três dimensões, e ter a ilusão de visão em profundidade.

A partir dessas considerações, começa a explanar sobre a nova forma de composição desenvolvida por Miró: sua pintura se liberta do aprisionamento imposto pela rigorosa lei do ritmo e do equilíbrio renascentista. O pintor catalão livra-se da tridimensionalidade, da exigência do centro do quadro e, mais significativamente, dos limites impostos pela moldura. Depois dessa conquista, houve uma crescente exploração das possibilidades dinâmicas da superfície, com a utilização de linhas, que surgem estrategicamente soltas na pintura, em posição essencial e que exigem movimento do espectador: sujeitam sua atenção e lhes dinamiza o olhar, reservando-lhe surpresas em seu percurso inusitado.

João Cabral enfatiza no processo de criação de Joan Miró “uma atitude de vigilância e lucidez no fazer" (2003, p. 712), que se identifica com o tipo de poesia que já produz e que produziria posteriormente à escritura do texto crítico em questão. Para Cabral, assim como para Miró, o gesto criador é sempre uma luta árdua e continuada. Aguinaldo 
Gonçalves, crítico e amigo do poeta, assevera que "a poesia de Cabral resgata a palavra. Reinventa-a, tornando-a, mais que designadora de algo, indicial, icônica e até mesmo gestual” (GONÇALVES, 1989, P. 2122).

Para construir essa poesia icônica, indicial e gestual, o poeta incorpora alguns aspectos de composição formal já utilizados por outros escritores de poesia moderna, porém de forma bastante particular. Ele mesmo enumerou onde se manifestam essas características, em discurso proferido no Congresso Internacional de Escritores, de 1954, em São Paulo:

... a - na estrutura do verso (novas formas rítmicas, ritmo sintático, novas formas de corte e "enjambement"); b - na estrutura da imagem (choque de palavras, aproximação de realidades estranhas, associação e imagística do subconsciente); c - na estrutura da palavra (exploração dos valores musicais, visuais e, em geral, sensoriais das palavras: fusão ou desintegração de palavras; restauração ou invenção de palavras, de onomatopéias) $d$ - na notação da frase (realce material de palavras, inversões violentas, subversão do sistema de pontuação); e e - na disposição tipográfica (caligramas, uso de espaços brancos, variações de corpos e famílias de caracteres, disposição simétrica dos apoios fonéticos ou semânticos (MELO NETO, 2003, P. 767 - 768).

Essas características e muitas outras empregadas por João Cabral dão ao texto poético um grande número de imagens icônicas, mobilizando a palavra e a sintaxe, de maneira que suscitem a potencialidade visual, figurativa dos versos. Para Paul Ricoeur (2007), um texto figurativo é um discurso que conduz ao pensamento de "uma coisa qualquer, considerando outra coisa qualquer de semelhante: é isso que constitui o modo icônico de significação” (RICOEUR, 2007, p. 286). Nesse sentido, assim como as metáforas recriam a significação das palavras, as imagens icônicas, articuladas no texto poético, rompem sua ligação com o referente imediato, e criam outros referentes a serem explorados pelo leitor atento.

Os referentes identificados na obra de Miró constituem expressão plástica de expressões poéticas, mais que de coisas: a pedra, a estrela, o 
pássaro são formas simples, limitadas de imagens, todavia, exploradas na pintura de Miró, transformam-se em "uma dupla luta, contra o estático próprio da cor e contra o estático próprio da contemplação de figuras conhecidas e apreendidas de memória" (MELO NETO, 2003, p. 704 - 705). A atitude do pintor é de completo abandono do já visto, do conhecido, do automatizado. Ele se despoja do hábito e procura descobrir novas formas de fazer pintura, dedicando-se à técnica do processo de pintura, valorizando ao extremo o trabalho criador. Para isso, desenvolve inúmeras pesquisas com matérias e técnicas gráficas variadas, indicando a criação lúcida de novas formas de expressão pictórica. No poema "O sim contra o sim", João Cabral descreve a forma como percebe o método criativo de Joan Miró:

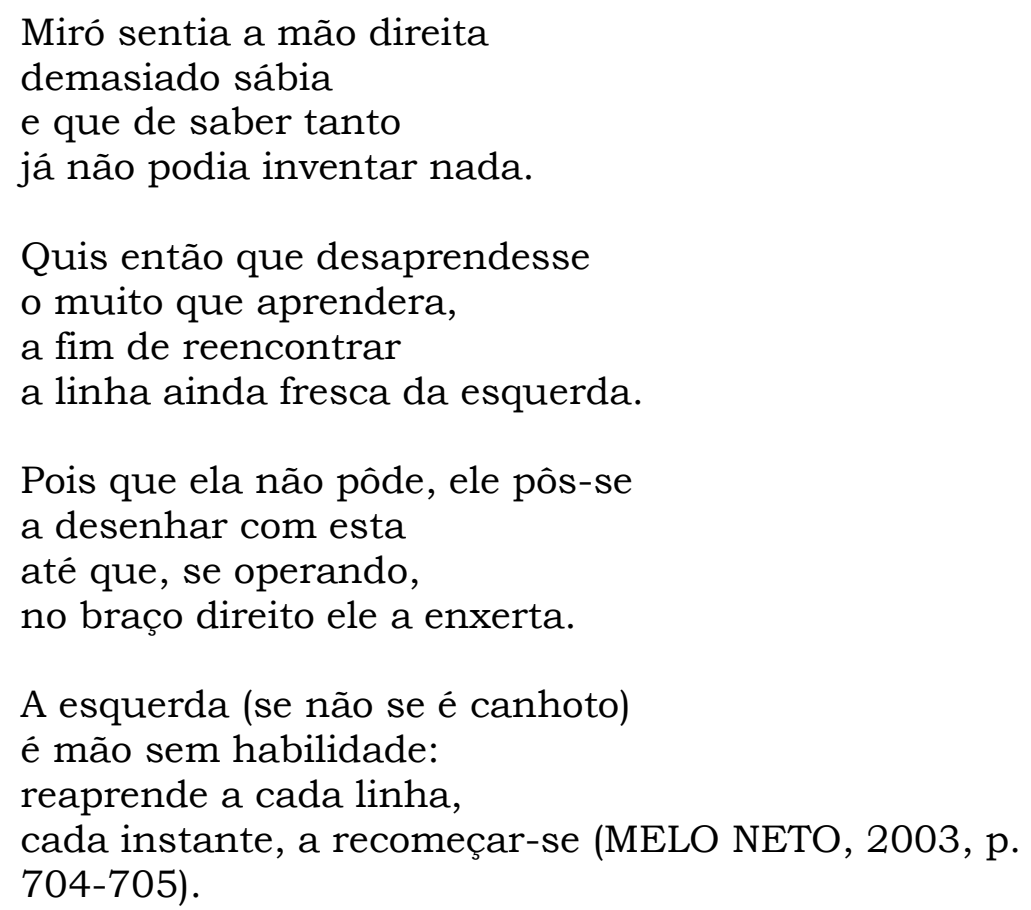

O crítico Sérgio Buarque de Hollanda (1978) encontra, no texto Miró, a revelação de um poeta que se afasta de toda tradição lírica e faz questão de demonstrar esse afastamento em sua produção poética, que busca a objetividade sem resvalar para as características do movimento realista. 
Miró tece fios em seus quadros dos quais é impossivel antever o destino, obrigando o espectador a açular sua atenção, acompanhando o movimento da linha que surge na tela. Na obra "Personagem lançando uma pedra para um pássaro"2, por exemplo, Miró traça uma linha contínua reta e outra pontilhada curva que cruza a primeira. Essas linhas sugerem a trajetória que a pedra fez e a que ainda está por fazer, apontando para um movimento, um processo que se desencadeia dinamicamente.

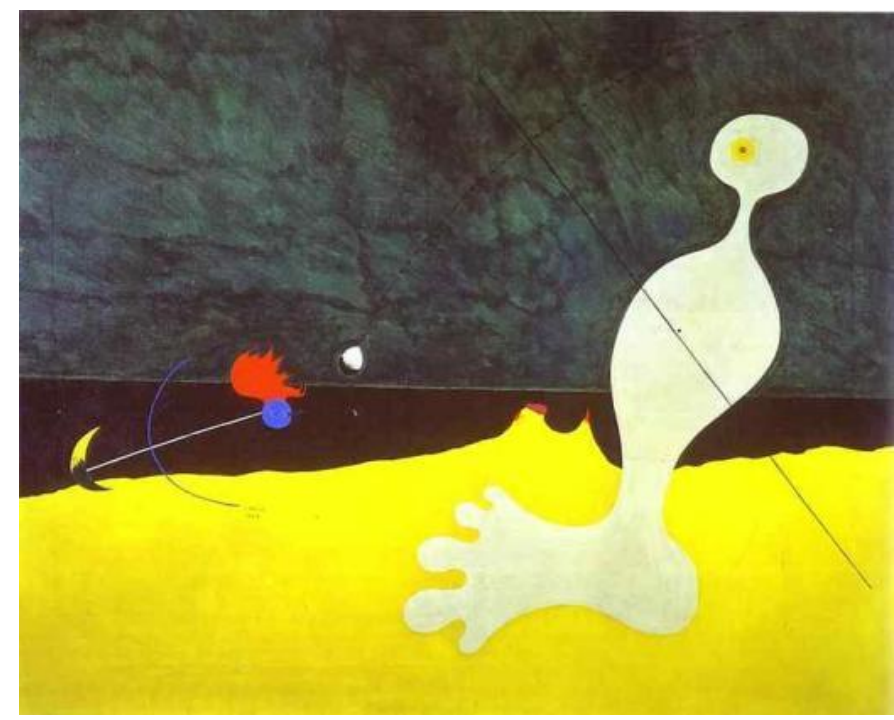

Personagem lançando uma pedra para um pássaro (1941)

A dinamicidade sugerida pela representação linear está explicitada no título dado ao quadro, em que o verbo "lançar" está no gerúndio. O movimento representado possui uma relação passado presente - futuro que configura o instante, o momento, como um flash. A pedra em movimento do quadro lembra o grão vivo de João Cabral que, na frase, cria obstáculo à leitura automática do poema, iscando o interesse do leitor:

\section{Catar feijão}

1

Catar feijão se limita com escrever:

2 "Personagem lançando uma pedra para um pássaro", 1926. Óleo sobre tela, 79 x 92 $\mathrm{cm}$. Museu de Arte Moderna de Nova Iorque. 
jogam-se os grãos na água do alguidar e as palavras na da folha de papel; depois, joga-se fora o que boiar. Certo, toda palavra boiará no papel, água congelada, por chumbo seu verbo: pois para catar esse feijão, soprar nele, e jogar fora o leve e oco, palha e eco.

\section{2}

Ora, nesse catar feijão entra um risco: o de que entre os grãos pesados entre um grão qualquer, pedra ou indigesto, um grão imastigável, de quebrar dente. Certo não, quanto ao catar palavras: a pedra dá à frase seu grão mais vivo: obstrui a leitura fluviante, flutual, açula a atenção, isca-a com o risco. (MELO NETO, 2003, p. 346-347).

João Cabral assevera que a obra de Miró "parece nascer da luta permanente (...) para limpar seu olho do visto e sua mão do automático" ( 2003, p. 711), na tentativa de libertar o pintor de toda a habilidade antes adquirida. Similarmente, o poeta adota uma postura severa diante do ato de criação: ele se impõe dificuldades, "catando" o vocábulo mais justo, a sintaxe mais precisa, a métrica e a rima mais sutis, empregando o octossílabo e as rimas toantes, quase imperceptiveis aos ouvidos desatentos. Essas e outras tantas técnicas demonstram que o poeta pernambucano possui a mesma "lucidez no fazer" que atribui ao pintor catalão.

O poema "Tecendo a manhã", de João Cabral de Melo Neto, evidencia a lucidez que o poeta exercita no processo de composição, resultando num texto que funde completamente o plano da expressão ao plano do conteúdo: no texto há plena vinculação entre "comunicação e composição" (BARBOSA, 1975, p. 218), pois os aspectos fonológico, lexical, morfológico e sintático conjugam-se harmonicamente na tessitura da manhã-poema: 
Tecendo a manhã

1

Um galo sozinho não tece uma manhã:

ele precisará sempre de outros galos.

De um que apanhe esse grito que ele

e o lance a outro; de um outro galo que apanhe o grito de um galo antes e o lance a outro; e de outros galos que com muitos outros galos se cruzem os fios de sol de seus gritos de galo, para que a manhã, desde uma teia tênue, se vá tecendo, entre todos os galos.

2

E se encorpando em tela, entre todos, se erguendo tenda, onde entrem todos, se entretendendo para todos, no toldo (a manhã) que plana livre de armação. A manhã, toldo de um tecido tão aéreo que, tecido, se eleva por si: luz balão. (MELO NETO, 2003, p. 345).

Em “Tecendo a manhã" ocorre uma mistura de competências de galos vizinhos, que, compartilhando sua cultura, constroem o tecido da manhã. O poema tem bases numa arquitetura de elipses e reiterações, de rupturas e enjambements, recursos estilísticos que estão em consonância com seus motivos poéticos: o canto do galo somente produz seus efeitos se lançado a outro, e assim sucessivamente, para que se faça a manhã (ou o amanhã). Um presente que não surtiria efeito se praticado espaço-temporalmente de forma isolada (repare no tempo presente do verbo negativo: “não tece"), mas somente se houver solidariedade entre os galos (homens, poetas), com intuito de construção do futuro comum. As elipses nos fazem procurar em outros versos o termo que complete o sentido da frase, assim como o encavalgamento mostra a relação de solidariedade entre os versos. Voltemos aos versos 3 a 8 , em que esses dois recursos (enjambement e elipse) fazem com que a leitura se desencadeie sem pausas, buscando no verso posterior o que antes estava ausente: 
De um que apanhe esse grito que ele e o lance a outro; de um outro galo que apanhe o grito de um galo antes e o lance a outro; e de outros galos que com muitos outros galos se cruzem os fios de sol de seus gritos de galo, (MELO NETO, 2003, p. 345).

Portanto, só encontramos o sentido do verso no todo do poema, em que as partes são indissociáveis e interdependentes, completando-se mutuamente, num processo de hibridismo comunitário.

A metáfora usada por João Cabral remete à necessidade humana de orientar-se para a construção de sua historia e de seu futuro, com base nas ações do presente. O grito lançado em busca da tessitura do amanhã é híbrido, portanto incompleto: a ação presente é uma fração do que já foi feito e do que ainda está por vir. O registro do presente é o incompleto; só se completa com o devir, mas quando este chega já é novamente o presente, e novas necessidades se descortinarão.

Nesse sentido, a expressão "tecendo a manhã" se encaixa perfeitamente na idéia de uma prática contínua (indicada pelo gerúndio). A visão em flash, de uma ação que que está sendo processada, nos remete às linhas contínuas e pontilhadas de Miró, e a muitas outras técnicas que o pintor empregou para mostrar a dinamicidade de sua pintura (muitas vezes explicitas também no título, como em “personagem atirando...”). Repare-se que Melo Neto aponta a fluidez da manhã, pela imagem do "tecido aéreo", que só poderá elevarse depois de tecido (o particípio passado indica ação concluída), o que, no presente, ainda é um processo em desencadeamento: "A manhã, toldo de um tecido tão aéreo / que, tecido, se eleva por si: luz balão”.

Em João Cabral, a fragmentação espaço-temporal da ação do galo está mais explícita, desde o primeiro verso, em que se ressalta a incapacidade de se construir algo de forma solitária, e a necessidade de unir forças para transformar a teia (prisão) e o toldo (sombra) em balão (luz e liberdade). Repare-se que Melo Neto utiliza o termo "grito", para referir-se ao canto dos galos, e esse grito é que desperta o outro galo 
para a ação presente, desencadeando um processo fragmentado, mas contínuo, de individualidades que se entrecruzam, enriquecendo-se solidariamente.

O que mais consolida a ideia de processo contínuo de construção do devir é a caracterização do resultado final como "luz balão", feita de "tecido aéreo". Há nessas expressões um sentido de clareza e liberdade, mas também de fragilidade e fugacidade, denotando um movimento em espiral, em que o fim nunca é atingido totalmente, mas antes, anuncia a necessidade de um eterno recomeço, para que o balão não extinga sua luz nem perca sua capacidade de voar. O lançar contínuo do grito é o suficiente para construir uma manhã, que sustenta um dia inteiro, mas não sustenta todas as manhãs vindouras, levando o galo a recomeçar sempre a cada madrugada, como se o fizesse pela primeira vez. Diante dessa constatação, o leitor é levado de volta ao início do poema, e a palavra "sempre" salta-lhe aos olhos: "Um galo sozinho não tece uma manhã: / ele precisará sempre de outros galos." O chamado de João Cabral para a construção de uma manhã livre, idéia utópica que se liga ao conceito de "sonho diurno", teorizado por Ernst Bloch (2005), acaba por remeter à concepção de poesia assumida pelo autor que cria em constante estado de vigilância e de busca de superação.

Curiosamente, esse poema, tão significativo no conjunto da obra de Melo Neto, remete ao quadro que conduziu o poeta pernambucano ao encontro do pintor catalão: "o galo" de Miró representa pictoricamente o que João Cabral representa por palavras:

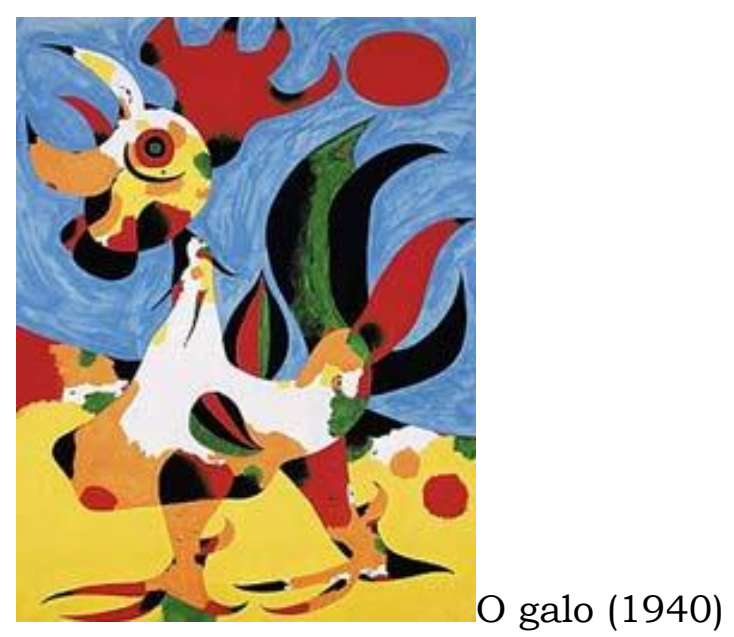


No canto esquerdo do quadro, Miró representa a figura de um sol vermelho que se encontra em baixa posição no céu, indicando um amanhecer em processo. À frente dele e ocupando grande parte da tela, em primeiro plano, Miró pinta um galo colorido, cujo bico, extremamente aberto e, assim como sua lingua e suas unhas, apresenta pontas extremamente afiadas. Parece lançar um grito de desafio e de chamamento. As cores empregadas, embora de tonalidades intensas, são poucas: o amarelo, o vermelho, o verde e o negro são as que mais se destacam. Há uma sintonia entre o vermelho e o verde, provocando uma sensação de vibração da tela, enquanto o preto perde sua função tradicional de contorno de figuras ou representação de sua sombra, ao contrário, proporciona a ela um contraponto às cores vibrantes, e criando uma sensação harmônica em relação ao branco do corpo da ave.

Joan Miró compôs "O galo"3 em Varengeville-sur-Mer, pequeno povoado do litoral da Normandia, para onde se mudou em 1936. Nesse período, o pintor prolongou por quatro anos sua estada na França, para se refugiar da Guerra Civil Espanhola, e lá permaneceu até maio de 1940, ano em que se registra a composição da referida tela. É sabido que, por esses tempos de extremo conflito em terras espanholas, Miró engajou-se na luta pelo restabelecimento do regime republicano na Espanha, juntando-se a artistas que compuseram obras contra o fascismo do general Franco. Nesse contexto, "o galo" adquire uma representatividade participativa e militante, lançando um alerta aos "outros galos", chamando-os a participar da construção de uma manhã liberta das amarras da opressão, assim como o pintor conseguiu libertar-se das amarras da pintura tradicional.

O poeta supera a velha polarização "arte pela arte" e "arte engajada", uma vez que suas obras, ao mesmo tempo em que são construídas de forma racional, pensada, utilizando recursos estilisticos

3 Título original: Le coq. Tela de 63.5 por $48.9 \mathrm{~cm}$. Composição em guache, aquarela e lápis, de 1940. 
como figuras inusitadas, encavalgamentos, rupturas, elipses, reiterações, concisão de linguagem, que as identificam com a arte pura, ele não se detêm nesse limite, pois também cuida do conteúdo com primazia, abordando criticamente temas sociais do seu tempo e do seu espaço, o que as tornam engajadas. Sobre o assunto, Benjamin Abdala Junior (2003) assevera que:

[...] a radicalidade exterior do escritor engajado só se efetiva concretamente num engajamento da radicalidade literária. Ao escritor participante ou militante é solicitado que ele tenha consciência crítica dos processos literários que utiliza (ABDALA JUNIOR, 2003, p. 110).

A preocupação de Abdala Junior é perfeitamente contemplada nas obras aqui estudadas. O poeta faz do exercício da radicalidade literária instrumento para a figuração crítica da realidade que os rodeia.

Apesar dos artistas apontarem para o futuro, ao indicarem o devir sonhado, ocorre manifestação desse futuro no presente das obras e, dessa forma, conseguem realizar aquilo que busca, não ficando somente no sonho utópico.

\section{Referências bibliográficas}

ABDALA JUNIOR, Benjamin. Algumas observações sobre a comparação entre escritores engajados das literaturas de lingua portuguesa. In: De vôos e ilhas. Literatura e comunitarismos. Cotia: Ateliê Editorial, 2003.

BARBOSA, João Alexandre. A imitação da forma: uma leitura de João Cabral de Melo Neto. São Paulo: Duas Cidades, 1975.

BLOCH. Ernst. O principio esperança. Rio de Janeiro: Contraponto/UERJ, 2005/2006. 
CASTELlO, José. João Cabral de Melo Neto: o homem sem alma. Rio de Janeiro: Rocco, 1996.

GONÇALVES. Aguinaldo. Transição e permanência. Miró/João Cabral: da tela ao texto. São Paulo: Iluminuras, 1989.

HOLLANDA, Sérgio Buarque de. Branco sobre o branco. In: Cobra de vidro. São Paulo: Perspectiva, 1978.

MELO NETO, João Cabral. Obra completa. Rio de Janeiro: Nova Aguilar, 2003.

RICOEUR, Paul. A memória, a história, o esquecimento. Campinas: UNICAMP, 2007. 